\title{
La neología en español relacionada con los business angels: un estudio de caso en el campo de la financiación alternativa
}

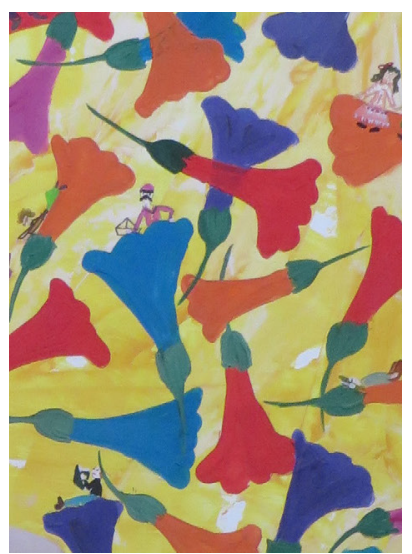

Beatriz de la Fuente Marina

Universidad de Salamanca, España

fuentemarina@usal.es

Trabajo recibido el 20 de abril de 2021 y aprobado el 27 de julio de 2021.

\section{Resumen}

En este artículo nos fijamos como objetivo contribuir al estudio de los procesos neológicos en un campo temático concreto, el de la financiación alternativa, a través del análisis pormenorizado de las unidades terminológicas en español relacionadas con los business angels. Para ello, hemos recopilado dos amplios corpora de textos especializados correspondientes a las variedades de España y de América. Además de obtener datos cuantitativos sobre la frecuencia de aparición de los términos, prestaremos atención a su delimitación conceptual (incluyendo los tipos de business angels) y a los criterios lingüísticos que intervienen en su formación, de manera que se proporcionen algunos puntos de anclaje para que el usuario (especialista, redactor técnico, traductor, etc.) tome decisiones fundamentadas a la hora de emplear estos neónimos en español.

Palabras clave: terminología, neología, financiación alternativa, business angels, ángeles inversores.

Spanish neology related to the business angels: a case study in the field of alternative financing

\footnotetext{
Abstract

My aim in this paper is to contribute to the study of neological processes in a specific thematic area, alternative financing, through the analysis of the Spanish terminological units that are related to business angels. To that end, I have gathered two extensive corpora of specialized texts for the varieties of Spain and America. Apart from obtaining quantitative data on the frequency of terms, I will pay attention to concept delimitation
} 
(including the types of business angels) and to linguistic criteria that will help the user (expert, technical writer, translator, etc.) to make informed decisions when using these neonyms.

Keywords: terminology, neology, alternative financing, business angels, angel investment.

\section{A neologia em espanhol relacionada aos business angels: um estudo de caso na área de financiamento alternativo}

\section{Resumo}

O objectivo deste artigo é contribuir para o estudo dos processos neológicos num campo temático específico, o do financiamento alternativo, através de uma análise detalhada das unidades terminológicas em espanhol relacionadas com business angels. Para o efeito, compilámos dois extensos corpora de textos especializados correspondentes às variedades de Espanha e América. Para além da obtenção de dados quantitativos sobre a frequência dos termos, prestaremos atenção à sua delimitação conceptual (incluindo os tipos de business angels) e aos critérios linguísticos envolvidos na sua formação, que ajudarão o utilizador (especialista, redactor técnico, tradutor, etc.) a tomar decisões informadas ao utilizar estes neónimos.

Palavras-chave: terminologia, neologia, financiamento alternativo, business angels, investidores anjos.

\section{Introducción y metodología}

En el campo de la microeconomía y, en particular, en el ámbito de la financiación alternativa (aquella que no procede de fuentes consideradas tradicionales como las subvenciones públicas o los créditos bancarios), apenas nos sorprende toparnos con extranjerismos crudos que el español toma prestados de la lingua franca imperante hoy día: bootstrapping, private equity, crowdfunding, crowdinvesting, crowdlending, business angels, family, friends and fools... Lo mismo sucede con el lenguaje del emprendimiento y las formas de trabajo colaborativo propiciadas por las nuevas tecnologías: spin-off, start-up, coworking, crowdsourcing. La profusión y aceptación de estos términos es tanta que el experto o intermediario acaba por renunciar a otras opciones neológicas de formación más natural en nuestra lengua, pero que presentan el inconveniente de estar poco implantadas y de convivir con numerosas denominaciones alternativas.

En este artículo nos fijamos como objetivo contribuir al estudio de los procesos neológicos en este campo temático a través del análisis pormenorizado de las unidades terminológicas en español relacionadas con los business angels. Asimismo, la delimitación conceptual y la consideración de los criterios lingüísticos que intervienen en la formación de los términos proporcionarán algunos puntos de anclaje para que el usuario (especialista, redactor 
técnico, traductor, etc.) tome decisiones fundamentadas a la hora de usar estos neónimos en español.

Bajo el encuadre metodológico de la Teoría Comunicativa de la Terminología ${ }^{1}$, desarrollada fundamentalmente por María Teresa Cabré (2005), nos proponemos observar el comportamiento de los términos in vivo, tal como aparecen en los textos especializados. Con el fin de ilustrar el estado de la cuestión en España y América, hemos reunido dos corpora diferenciados para estas dos grandes variedades diatópicas, aun siendo conscientes de las diversidades que subsume el denominado "español de América". Los 180 textos (117 para el corpus de España, 63 para el corpus de América) dan cuenta igualmente de la variación vertical, referida al grado de especialización (Hoffmann 1985), pues incluyen desde documentos altamente especializados (monografías y artículos en revistas de alto impacto) hasta textos de corte académico y/o didáctico (tesis doctorales, trabajos de fin de máster y de grado, cursos para asignaturas universitarias), así como legislación (BOEs y comunicaciones de la Unión Europea), y otros textos de tenor más divulgativo ${ }^{2}$, pero cuyo emisor suele ser un especialista o un intermediario experto en el ámbito (folletos explicativos elaborados por las redes de business angels, artículos o notas de prensa en las secciones temáticas correspondientes de la prensa seria). No hay que olvidar que -como ocurre de manera más notable con el crowdfunding, precisamente porque apela a un público amplio—, la esfera terminológica de los business angels está en vías de inundar la lengua general, lo cual legitima la consideración de estos textos divulgativos, que pertenecen a la escala más baja de especialización.

El grueso de los documentos de los corpora ha sido publicado después de 2010, por lo que los resultados reflejan el estado de la cuestión en

1 María Teresa Cabré propone una teoría de la terminología de base comunicativa con el fin de complementar a la "Teoría General de la Terminología (TGT), desarrollada por la escuela vienesa y basada en las propuestas de Wüster [...] La característica más relevante de la TGT es que centra la atención de la disciplina en los conceptos, y orienta los trabajos terminológicos hacia la normalización de términos y nociones", con un "enfoque desde el concepto al término (onomasiológico)". Esta TGT "da muestra de reduccionismo en diferentes aspectos de sus concepciones y de sus prácticas: la concepción global de la unidad terminológica, la reducción de la unidad terminológica a su condición denominativa, el olvido de los aspectos sintácticos de las unidades terminológicas, la ignorancia de los aspectos comunicativos de los términos, o la insistencia en negar la variación formal y conceptual de los términos". Asimismo, "la teoría terminológica tradicional se basa en una pretendida homogeneidad que no confirman los datos empíricos relativos a los distintos ámbitos temáticos, las finalidades aplicadas, o la defensa de una única metodología". La Teoría Comunicativa de la Terminología, por su parte, pretende dar cuenta de la complejidad del fenómeno terminológico en el marco de la comunicación especializada, considerando la vertiente comunicativa (pragmática) de las unidades terminológicas, "que identifican al hablante por la forma en que las utiliza en situaciones de expresión o comunicación determinadas". Esta "nueva versión de la terminología como disciplina" ha de permitir "dar cuenta tanto de su función representacional como comunicativa, de su materialización en distintos niveles de formalidad (distintos niveles del discurso especializado) y para materias especializadas de estructuras muy diversas (experimentales, teóricas, humanas y sociales, actividades especializadas)" (todas las citas de esta nota proceden de Cabré Castellví 2005, 20 y ss.).

2 Una de las características de la Teoría Comunicativa de la Terminología es la atención a las situaciones comunicativas reales, "que admiten esquemas e interlocutores diversificados que abren necesariamente el esquema de comunicación clásico de especialista a especialista a otras posibilidades de interlocución (el discurso didáctico o divulgativo)" (Cabré Castellví 2005, 212). Así pues, consideramos justificada la inclusión de textos de corte divulgativo cuyo emisor, no obstante, es un especialista en este ámbito de la microeconomía. Ya Lothar Hoffmann había aludido a la variación vertical de las lenguas de especialidad ("die vertikale Schichtung der Fachsprachen", 1985, 64), con la que proponía la existencia de registros o niveles de estilo también en la comunicación especializada, en contra de la tendencia tradicional, que la consideraba una esfera "sobria" en la que no tenían cabida las variantes expresivas. 
el momento actual. Para la exploración hemos utilizado la herramienta Terminus 2.0 de la Universidad Pompeu Fabra de Barcelona.

\section{Business angel como hiperónimo}

Empezamos delimitando conceptualmente el término business angel. Mason y Harrison (citado en Hoyos Iruarrizaga y Blanco Mendialdua 2014, 149-150) lo definen de la siguiente manera: "Individuo con elevado poder adquisitivo que, actuando solo o sindicado formal o informalmente con otros, invierte su propio dinero de manera directa en un negocio no cotizado, con el que no existe un vínculo de tipo familiar, tomando parte activa en el desarrollo del negocio, bien como asesor o miembro de la junta directiva".

Dentro del proceso secuencial de financiación del emprendimiento, los business angels se sitúan hacia el final de la fase de gestación de una empresa o proyecto, o bien al inicio de la fase de crecimiento y expansión. Se consideran una fuente de financiación alternativa porque cobran auge especialmente a raíz de la crisis económica iniciada en 2008, cuando la dificultad para obtener ayudas públicas (ya directas, como subvenciones, créditos blandos y anticipos reembolsables; ya indirectas, como incentivos fiscales) llevan al emprendedor a buscar fuentes no tradicionales para poner en marcha su idea de negocio: la denominada "financiación de proximidad", proporcionada por el círculo de familiares y amigos; el crowdfunding, consistente en hacer un llamamiento masivo a través de la red a un colectivo de personas con el fin de que aporten su dinero a cambio de ciertas contraprestaciones (acciones, intereses, productos, prestación de servicios, o simplemente reputación o satisfacción); y los business angels, inversores particulares que además de capital -y esto es distintivo- suelen aportar también conocimiento y contactos (lo que se conoce como 3Cs), e incluso confianza (las 4Cs). La diferencia de los business angels respecto a la "financiación de proximidad" reside en que invierten en determinados negocios sin tener, en principio, ninguna relación con los emprendedores. Además, invierten su propio dinero, lo que los distancia del capital riesgo tradicional, en el cual los inversores manejan fondos de terceras personas.

Como en otras ocasiones, el signatum (el concepto, 'lo designado') surge antes que el signum (el significante), según la terminología de Jakobson (1959, 232 y ss.). En el caso de los business angels, se puede documentar el largo recorrido del término angel en lengua inglesa, ya que en torno a 1900 encontramos en Broadway a los theatre angels, unas figuras dispuestas a costear producciones teatrales con un elevado nivel de riesgo (de Torres Carbonell 2012, 53). La descripción ofrecida por Viel proyecta sobre esa figura muchos de los rasgos definitorios de un business angel profesional: 


\begin{abstract}
Estados Unidos. Además de recibir capital, las productoras se beneficiaban por la aportación del inversor en el negocio ya que este aportaba su conocimiento y contactos. Los inversores, a cambio, recibían un porcentaje del dinero recaudado por las entradas vendidas para cada función (Viel 2014, 12).
\end{abstract}

También se señala como inversión ángel en cierto modo inaugural el préstamo de 500 dólares que Frederick Terman, del Departamento de Ingeniería de la Universidad de Standford, hizo en 1938 a dos de sus licenciados, Bill Hewlett y Dave Packard, los futuros fundadores de la famosa firma electrónica Hewlett-Packard (Colomer i Espinet et al. 2009, 43; Hoyos Iruarrizaga y Saiz Santos 2014, 26). Se podría decir que "los apadrinó en los primeros años de su carrera como nuevos empresarios" (Colomer i Espinet et al. 2009 , 43). Pero no sería hasta principios de los ochenta cuando William Wetzel Jr., de la Universidad de New Hampshire, acuñara el sintagma business angel (Romaní y Atienza 2017, 2).

A propósito del apadrinamiento, abrimos ahora un breve excurso para adelantar una de las recomendaciones neológicas que se han propuesto para nuestra lengua, la que realizó la Fundación del Español Urgente en 2013, según la cual los sintagmas "padrino inversor" o "padrino empresarial" serían adecuados para sustituir al anglicismo "innecesario" business angel. No sorprende demasiado que no aparezca "ángel" como núcleo del sintagma: en inglés también se utilizaba la alternativa business investor, que finalmente cedió ante business angel (angel investor era otra de las variantes de baja frecuencia). Pero lo cierto es que la propuesta de la Fundéu registra muy pocas ocurrencias en los textos de nuestro corpus, además de presentar el inconveniente de distanciarse de la familia léxica española, que incluye unidades como "inversión ángel" o "fondo ángel”3.

Recogemos primeramente los resultados que arrojan nuestros corpora para business angel como hiperónimo, indicando la frecuencia absoluta y el tipo de unidad de que se trata. Comencemos por la variante peninsular del español:

3 Lo que sí encajaría en la propuesta "padrino inversor" o "padrino empresarial” sería la doble naturaleza que puede esconder esta figura. En efecto, los textos especializados mencionan entre los tipos de business angels una categoría que solo sería un "ángel” por antífrasis: el business devil, demonio o diablo de los negocios, que se aprovecha negativamente de la inexperiencia del emprendedor (Schramm 2010, 9), o bien que acapara más del 50\% del capital social de la iniciativa de negocio (Hoyos Iruarrizaga y Saiz Santos 2014, 32). 


\begin{tabular}{|c|c|c|}
\hline Término & Frecuencia & Tipo de unidad \\
\hline business angel & 2.686 & Extranjerismo crudo (sintagma $[\mathrm{N}+\mathrm{N}]$ ) \\
\hline ángel inversor & 611 & Sintagma $(N+A d j)$ \\
\hline BA & 92 & Sigla (por las iniciales en inglés) \\
\hline inversor ángel & 14 & Sintagma $(N+N)$ \\
\hline ángel de los negocios & 10 & Sintagma (N + S. Prep) \\
\hline padrino inversor & 7 & Sintagma $(N+A d j)$ \\
\hline ángel inversionista & 5 & Sintagma $(N+A d j)$ \\
\hline ángel financiero & 4 & Sintagma $(N+A d j)$ \\
\hline inversor angelical & 4 & Sintagma $(N+A d j)$ \\
\hline ángel de negocios & 5 & Sintagma (N + S. Prep) \\
\hline inversor providencial & 3 & Sintagma $(N+A d j)$ \\
\hline inversionista ángel & 2 & Sintagma $(N+N)$ \\
\hline mentor empresarial & 2 & Sintagma $(N+A d j)$ \\
\hline mecenas financiero & 1 & Sintagma $(N+A d j)$ \\
\hline padrino empresarial & 1 & Sintagma (N + Adj) \\
\hline
\end{tabular}

Tabla 1. Business angel como hiperónimo en el corpus de España.

Se observa un absoluto predominio del préstamo sin adaptar (extranjerismo crudo). Las alternativas que se han propuesto en español registran comparativamente una frecuencia baja, solo a excepción de "ángel inversor", que calca el núcleo del sintagma inglés, manteniendo la metáfora religiosa del "ángel" pero incidiendo en su capacidad inversora, en lugar de la "empresa" o "negocio", receptores prototípicos de sus fondos. El sintagma quiástico "inversor ángel" registra tan solo 14 ocurrencias, y además puede plantear dudas a los usuarios sobre el plural del sustantivo en aposición: los textos fluctúan entre "inversores ángel" e "inversores ángeles" (ambos correctos según las reglas de formación del plural recogidas en el Diccionario panhispánico de dudas [2005, 507, §2.4]). La variante "inversionista ángel" es más frecuente en el corpus americano. En tercer lugar, por orden de frecuencia se sitúa la sigla "BA", por las iniciales del término anglosajón; en los textos españoles se prefiere el plural "BA" sin ese final (frente al inglés $B A s$ ). La baja ocurrencia del resto de unidades parece indicar que sus posibilidades de implantación real en el discurso especializado durante los próximos años serán escasas. Hallamos sintagmas con "ángel” como núcleo: "ángel de los negocios" y la variante sin preposición "ángel de negocios", "ángel financiero", así como "ángel inversionista", mucho más usado en América. Un segundo grupo elige otro núcleo distinto, como el ya mencionado "padrino" ("padrino inversor" y "padrino empresarial"), o bien "mentor" o "mecenas", ambos de onomásticos de la esfera grecolatina. Por último, tenemos construcciones análogas a "inversor ángel", pero con un adjetivo que recoge la alusión metafórica ("angelical" o "providencial"), en lugar del sustantivo "ángel".

Estos son los datos que ofrece el corpus de América: 


\begin{tabular}{lcc}
\hline Término & Frecuencia & Tipo de unidad \\
\hline business ángel & 315 & Extranjerismo crudo (sintagma $[\mathrm{N}+\mathrm{N}])$ \\
\hline ángel inversionista & 206 & Sintagma $(\mathrm{N}+\mathrm{Adj})$ \\
\hline inversor ángel & 185 & Sintagma $(\mathrm{N}+\mathrm{N})$ \\
\hline inversionista ángel & 168 & Sintagma $(\mathrm{N}+\mathrm{N})$ \\
\hline Al & 59 & Sigla (por las iniciales en español) \\
\hline ángel inversor & 20 & Sintagma $(\mathrm{N}+\mathrm{Adj})$ \\
\hline ángel aportador & 12 & Sintagma $(\mathrm{N}+\mathrm{Adj})$ \\
\hline BA & 4 & Sigla (por las iniciales en inglés $)$ \\
\hline ángel de los negocios & 1 & Sintagma $(\mathrm{N}+\mathrm{S}$. Prep) \\
\hline ángel de negocios & 1 & Sintagma $(\mathrm{N}+\mathrm{S}$. Prep) \\
\hline inversor providencial & 1 & Sintagma $(\mathrm{N}+\mathrm{Adj})$ \\
\hline mecenas financiero & 1 & Sintagma $(\mathrm{N}+\mathrm{Adj})$ \\
\hline padrino inversionista & 1 & Sintagma $(\mathrm{N}+\mathrm{Adj})$ \\
\hline padrino inversor & 1 & Sintagma $(\mathrm{N}+\mathrm{Adj})$ \\
\hline
\end{tabular}

Tabla 2. Business angel como hiperónimo en el corpus de América.

Aunque el extranjerismo crudo sigue ocupando aquí la primera posición, hay tres denominaciones que aparecen con una frecuencia notable en el español de América: "ángel inversionista", "inversor ángel" e "inversionista ángel". Como se observa, todas estas construcciones aparecían en el español peninsular, con la diferencia de que ahora las unidades formadas por el adjetivo "inversionista", o su sustantivación (en lugar de "inversor"), pasan a los primeros puestos de la tabla. Sin embargo, "ángel inversor", el único sintagma que en España podía competir de alguna manera con el anglicismo, desciende ahora al sexto lugar. Efectivamente, "inversor ángel" y "ángel inversor" han intercambiado posiciones en ambos corpora. Asimismo, aparece una unidad nueva, "ángel aportador". Por otro lado, sorprende la aparición de una sigla, "AI", a partir de las iniciales del término en español ("ángel inversionista" o "ángel inversor"), y sobre todo que gane terreno a "BA" (lo que podría apuntar a la expansión de la unidad española en detrimento de la inglesa). La presencia de las demás alternativas hispanas es muy baja. Junto a "padrino inversor" encontramos "padrino inversionista", como cabía esperar. El resto de las opciones aparecía también en el corpus de España, y en cambio han desaparecido "inversor angelical", "ángel financiero", "padrino empresarial" y "mentor empresarial".

Según estos datos, contamos en español con 18 denominaciones alternativas para business angel, y resulta inevitable preguntarse por el origen de tan acusada variación. Si pensamos en divergencias intertextuales, la respuesta más plausible es la ofrecida por Pruvost y Sablayrolles (2003, 67), quienes se refieren a este fenómeno de "creaciones escalonadas": distintos hablantes, que no tienen a su disposición un equivalente para el término inglés, crean neologismos de manera casi simultánea, independientemente unos de otros, lo que explicaría la enorme variación que se da en 
nuestro caso de estudio. Se trataría, con todo, de variación denominativa, no conceptual. Como apunta Judit Freixa $(2005,122)$, en los casos en que la variación se produce entre diferentes fuentes, el grado de equivalencia entre las denominaciones que han seleccionado los diferentes autores suele ser muy elevado, tratándose las más de las veces de una variación involuntaria (en el sentido de que el hablante desconoce, o no está seguro, de las posibilidades que ofrece el léxico).

Por otro lado, resulta un tanto paradójica la variación intratextual en algunos de los documentos de nuestros corpora, pues ello atenta contra la pretendida biunivocidad del discurso especializado. He aquí algunos ejemplos (el subrayado es mío):

a) Los inversionistas privados, llamados también inversionistas "ángeles" $o$ "business angels", son agentes clave en la financiación y el apoyo a emprendedores. El inversor "ángel" cubre una brecha significativa en el ciclo financiero del emprendimiento que oscila entre los 50.000 dólares y un millón de dólares. A pesar de la importante aportación de los "ángeles" inversionistas a los emprendimientos, la experiencia internacional demuestra que el desarrollo de este tipo de inversión encuentra numerosas trabas... (Roure et al. 2013, 3 y 7).

b) Los Ángeles Inversores (AI) son personas con altos recursos económicos que invierten su propio dinero en empresas con alto potencial de crecimiento que no cotizan públicamente, y no tienen relaciones familiares con el equipo fundador del emprendimiento. Los inversores ángeles juegan un rol crítico en el financiamiento de estos (sic) emprendimiento (...). Generalmente un inversionista ángel debe estar dispuesto a invertir entre el $5 \%$ y $10 \%$ de su portafolio total de activos en empresas jóvenes (Ayala Pintado y González Alvarado 2010, 10 y 13).

c) Ángeles inversores o business angels. (...) Sin embargo el número estimado de ángeles inversores y la inversión media por ronda sigue por debajo, así como el total invertido por business angels en 2009, donde se ven aún grandes diferencias (Olmos García 2014, 30 y 32).

Estos tres contextos de uso comparten la circunstancia de estar extraídos de obras que trazan un marco teórico sobre esta nueva modalidad de inversión. Ofrecen información valiosa no solo respecto a la delimitación conceptual y a las variantes denominativas, sino también acerca de los elementos que las introducen. Pese a la reciente fecha de publicación de los textos, encontramos toda una serie de marcas que dan cuenta de la inestabilidad de los términos en cuestión: ninguno de ellos ha conseguido asentarse de manera definitiva frente a los demás y, por tanto, se puede afirmar que estamos asistiendo al proceso neológico en pleno desarrollo. Así, el ejemplo (a) parece una pequeña enciclopedia de marcas neológicas: se utilizan las comillas, curiosamente para resaltar solo el componente metafórico del sintagma (inversor "ángel"); la cursiva con la doble marca de las comillas ("business angels"); metalenguaje ("llamados también..."); y una acumulación de cinco sinónimos, entre los que se incluye uno que funciona como sinónimo contextual, "inversionista privado", aunque en realidad es un hiperónimo de business angel (frente al inversor institucional, el 
inversor privado invierte su propio dinero, no el de otras personas, pero no todos los inversores privados entrarían automáticamente en la categoría de business angels, ya que estos, además de capital, aportan prototípicamente también sus conocimientos, experiencia y red de contactos). Parece que en este caso el emisor introduce repeticiones y paráfrasis en aras de una mayor claridad (el receptor conocerá sin duda alguna de las variantes), demostrando a un tiempo que la redundancia no está ausente en los textos especializados (Cabré y Estopà Bagot 2005, 76). El ejemplo (b) transmite un ansia de inteligibilidad similar: presenta varias unidades sinónimas en español, pero las autoras parecen renunciar conscientemente al anglicismo, que no usan en todo el documento, salvo en los nombres de redes que incorporan business angels en su denominación; ofrecen asimismo entre paréntesis una sigla española ("AI") alternativa a la inglesa ("BA", utilizada con profusión en el corpus de España). A pesar de tratarse de un texto especializado, tampoco se puede descartar la voluntad de las emisoras de aligerar estilísticamente la redacción, en la línea de lo que ocurre, por ejemplo, en los textos periodísticos. En cambio, la autora del ejemplo (c) nos parece más sistemática: al utilizar la cursiva para business angels, se presenta como mera "transmisora" de un neónimo que no ha creado (Pruvost y Sablayrolles 2003, 71), pero considera conveniente especificar, mediante una conjunción disyuntiva, que es equivalente de "ángeles inversores", única denominación española que emplea en todo el texto.

Lo cierto es que, a la luz de los documentos más recientes de nuestros corpora, no podemos dar por concluido el proceso neológico. Continuamos encontrando alusiones a la etimología y traducción de los términos (“'business angel' traducido al español como 'inversionista ángel'”, Romaní y Atienza 2017, 2), y se sigue utilizando la cursiva para business angel (por ejemplo, Roure y de San José 2017) y las comillas para las denominaciones en español ("ángeles inversores" en un artículo de bancat.com, 2017), así como paráfrasis, aposiciones y definiciones de los términos en su primera mención (“Un inversionista ángel es aquel que lleva su capital a una empresa, startup o emprendimiento y a cambio se queda con un porcentaje de participación", Diario Financiero, 2018). Parece que los emisores (ya expertos, ya intermediarios) tienen todavía algunas prevenciones a la hora de usar estos neónimos en solitario ${ }^{4}$.

Un fenómeno contrapuesto es la abreviación de las unidades sintagmáticas a partir de la segunda mención, como ocurre en los siguientes contextos:

d) Fernández añade dos diferencias entre los fondos de inversión y un ángel: el fondo tiene "una tesis más definida, más a largo plazo, y el ángel

4 Esta manera de proceder recuerda al método adoptado en el siglo XV por Alfonso de Cartagena en sus traducciones del latín al castellano, consistente en introducir una "declaración", explicación o glosa del neologismo en su primera ocurrencia para asegurarse de que el receptor supiera identificar el concepto: " $Y$ donde el vocablo latino del todo se pudo en otro de romance pasar, hícelo; donde no se pudo buenamente por otro cambiar, porque a las veces una palabra latina requiere muchas para se bien declarar y si en cada lugar por ella todas aquéllas se hubiesen de poner harían confusa la obra, en tal caso al primero paso en que la tal palabra ocurrió se hallará declarada. Y, aunque después se haya de repetir, no se repite la declaración, mas quien en ella dudare retorne al primero lugar donde se nombró, el cual está en los márgenes señalado, y verá su significación" (Cartagena 2009, xxxvi). 
es más oportunista, es meterse en un proyecto que le dé rentabilidad, que funcione en una base por contrato, mientras que los fondos están mucho más estructurados". El monto del capital que ofrecen también hace la diferencia: mientras que "los ángeles invierten entre 250,000 y hasta 2 millones de pesos, los fondos de inversión están en el rango de los 2 millones en adelante", dice (Morales 2015).

e) Para estimar cuánta TIR es necesaria para que un business se enamore de tu startup es necesario entender antes el nivel de riesgo que está dispuesto a admitir (Otero Barros 2015).

En el contexto (d), extraído de un artículo publicado en Forbes México, se trunca el término "inversionista ángel" que aparece en la primera mención; por tanto, se elimina el núcleo y se mantiene el sustantivo que funcionaba como aposición y portaba el contenido metafórico. En (e) también se elimina el núcleo del sintagma anglosajón business angel, que en la lengua de origen se coloca en segundo lugar, perdiéndose en este caso el contenido metafórico, que no obstante se puede recuperar por el contexto (de lo contrario, "un business" sería simplemente un negocio o empresa). En ambos casos, se trata de textos redactados para medios especializados en economía, pero de clara vocación divulgativa. En particular el segundo, cuyo autor, Carlos Otero, se define como emprendedor y coach de start-ups, opta por un tono claramente informal, pues se dirige a una segunda persona del singular cuyo perfil es el de un empresario ya iniciado al que se le ofrecen consejos "de tú a tú". Este tipo de textos son interesantes porque parecen compartir algunas características con la oralidad (también el contexto (d) reproduce una entrevista -oral, asumimos- al fundador de una red de business angels mexicana).

Por último, cabe precisar que no hemos incluido en las tablas de frecuencia los hiperónimos de business angel que funcionan circunstancialmente como sinónimos de esta misma unidad, ya que los datos cuantitativos no reflejan si entra en juego una relación de hiperonimia o de sinonimia. Además del ya mencionado "inversor privado", se utilizan como sinónimos contextuales de business angel "inversor particular" (concepto análogo al de "inversor privado", por oposición al "inversor institucional") y, de manera menos precisa, "inversor informal"5 e "inversor de proximidad":

f) [...] incrementar el volumen de inversión en fondos de capital riesgo y los instrumentos de inversión promovidos por los denominados inversores informales ("ángeles financieros") (Artículo 11 de la Decisión núm. 1639/2006/CE del Parlamento Europeo y del Consejo, de 24 de octubre de 2006, citado en Montero Simó 2013, 216, n. 4).

g) Nuestro sistema tributario contiene diversas medidas previstas para incentivar la actividad de los inversores de proximidad o "business angels" en el ámbito del Impuesto sobre Sociedades (Rufino Bengoechea 2011).

5 Sin embargo, la literatura especializada (por ejemplo, Hoyos Iruarrizaga y Saiz Santos 2014) suele establecer una diferenciación entre el business angel y el "inversor informal": aunque los dos invierten a título individual en compañías no cotizadas, el primero tiende además a realizar un trasvase de capital inteligente (experiencia, contactos), mientras que el segundo no se implicaría activamente en los proyectos que financia. Por su parte, el "inversor de proximidad" suele tener un vínculo afectivo con el emprendedor (son sus familiares, amigos, colegas) y no siempre espera un retorno económico (a veces ni siquiera recuperar lo invertido, lo que obviamente no es el caso de los business angels). 


\section{Hipónimos de business angel}

Entre las fuentes de financiación alternativa, algunas, como el crowdfunding, han sido objeto de sistematización por parte de los expertos y su tipología se ha incluido ya en bases terminológicas como IATE y TERMCAT. No sucede así con la categorización de los business angels. Los textos no solo presentan distintos grados de complejidad, sino que incurren en una gran variación denominativa y conceptual.

Colomer i Espinet et al. $(2009,45)$ establece una cuidada tipología de business angels según diversos parámetros: en función de su nivel de actividad, se clasifican en business angels pasivos y operativos (otros autores prefieren hablar de "activos"); según su función dentro de la empresa, distingue entre business angels empresariales, trabajadores, consultores y financieros; y, en función de su número, encontramos business angels individuales y sindicados.

Basándose en la clasificación de Coveney y Moore de 1988, la guía elaborada en el marco del proyecto europeo LACES (Interreg España-Portugal) añade otro parámetro, la cantidad de capital invertido por el business angel, según la cual se distinguen seis tipos: corporate angel, entrepreneur angel, "el ángel buscador de ingresos", wealth maximizing angel, virgin ángel y latent angel. Las secciones van encabezadas por estos términos anglosajones sin traducir (salvo income seeking angel), aunque en el cuerpo del texto se observa un esfuerzo por ofrecer equivalentes ("business angel corporativo", "business angel emprendedor"), definiciones ("Virgin Angel. Son particulares que nunca han realizado inversiones informales, pero tienen tendencia a hacerlo en el futuro") o información metalingüística ("Wealth maximing angels. Como su propio nombre indica, su objetivo principal es maximizar su capital"). Otra obra argentina (Ruiz Igoa 2016, 23), basándose en la misma fuente, no hace referencia a los términos ingleses, sino que los traduce desde el principio: "ángeles maximizadores de riqueza", "ángeles emprendedores", "ángeles buscadores de ingresos", "ángeles corporativos", "ángeles vírgenes", "ángeles latentes". A su vez, las obras españolas de Hoyos Iruarrizaga y Blanco Mendialdua (2014) y de Hoyos Iruarrizaga y Saiz Santos (2014), muy informativas y didácticas, presentan una cantidad ingente de términos ingleses para los que no se ofrece equivalente (además de los mencionados, business devil, high-tech angel, pure business angel, technology angel, super angel, lead angel, etc.).

Se puede colegir que los autores adoptan una actitud metodológica distinta. Frente a los que optan por naturalizar los términos, los partidarios de los extranjerismos crudos pueden tener razones de peso para no traducir. En los proyectos europeos, como el mencionado Interreg, la lengua de trabajo suele ser el inglés, hecho que obviamente favorece el recurso al préstamo sin adaptar (asimismo, el grueso de la legislación comunitaria se discute y redacta primeramente en inglés y solo después es traducida al resto de lenguas). En el caso de textos de referencia elaborados por docentes (Hoyos Iruarrizaga y Saiz Santos son profesores de la Universidad del País Vasco), y siendo el público de destino principalmente estudiantes o futuros emprendedores de vocación internacional, se privilegia el acceso 
a la terminología por la vía del inglés, lingua franca de los negocios. Esta diversidad de enfoques se refleja en los resultados de nuestros corpora, donde las distintas denominaciones presentan una ocurrencia muy baja (siempre menos de 12), existiendo a un tiempo cierta variación conceptual (como en los casos del business devil o del "ángel pasivo").

Presentamos a continuación los principales tipos de business angels que aparecen en los textos, con indicación de las denominaciones alternativas, si las hay, para España (ES) y América (AM), ateniéndonos exclusivamente a los resultados de nuestro corpus (el asterisco indica un extranjerismo para el que no hemos hallado denominación en español). En la definición, señalamos la fuente principal en que nos hemos basado y, cuando procede, reflejamos la variación conceptual:

"Business angel activo (ES) / business angel operativo (ES) / ángel activo (ES y AM) / ángel inversionista activo (AM): business angel que realiza una aportación de valor plena, utilizando su conocimiento, habilidades y experiencia para asesorar y controlar la inversión de una manera cercana y directa (Hoyos Iruarrizaga y Saiz Santos 2014).

»Business angel pasivo (ES) / ángel pasivo (ES y AM) / ángel inversionista pasivo (AM): business angel que realiza un control periódico de su inversión y cuya implicación se limita a un asesoramiento puntual desde una perspectiva estratégica, o a un seguimiento de acuerdo con los términos de contrato (Hoyos Iruarrizaga y Saiz Santos 2014). Persona que, aunque ha investigado, aún no ha realizado ninguna inversión ángel (García Martínez, 2014).

"Business angel individual (ES) / ángel individual (ES) / ángel inversionista individual (AM) / inversor ángel individual (AM): business angel que actúa de forma personal e individual, sin requerir, por el volumen de inversión del proyecto empresarial, la entrada de más socios (Colomer i Espinet et al. 2009).

» Business angel sindicado (ES) / ángel inversionista sindicado (AM): business angel que invierte de manera conjunta en proyectos que requieren un nivel de inversión elevado o una diversificación del riesgo (Colomer i Espinet et al. 2009).

» Business angel corporativo (ES)/ángel corporativo (ES y AM) / inversionista ángel corporativo (AM) / ángel inversionista corporativo (AM): compañía que invierte regularmente con una modalidad similar a la del inversor ángel individual, adquiriendo en general grandes cantidades de acciones de las compañías en las que invierte (Ruiz Igoa 2016).

» Business angel emprendedor (ES) / ángel emprendedor (ES) / inversionista ángel emprendedor (AM): emprendedor de éxito y con grandes recursos económicos que, movido por el espíritu empresarial, invierte en nuevos proyectos de otras personas como una alternativa a las inversiones del mercado de valores (Adaptado de Parque Científico de la Universidad de Valencia 2017).

" Business angel a la caza de ingresos (ES) / ángel buscador de ingresos (ES y AM): business angel que invierte pequeñas cantidades y busca obtener ingresos periódicos, por ejemplo, ocupando un puesto directivo dentro de la compañía en la que invierte (Hoyos Iruarrizaga y Saiz Santos 2014). 
» Ángel maximizador de la riqueza (ES) / ángel maximizador de riqueza (ES y AM): individuo de alto poder adquisitivo y amplia experiencia que combina simultáneamente diferentes inversiones en start-ups (Hoyos Iruarrizaga y Saiz Santos 2014).

» Ángel virgen (ES y AM)/ángel potencial (ES) / inversor informal potencial (ES): persona con fondos disponibles que desea hacer su primera inversión en proyectos start-up, pero nunca ha dado el primer paso (Hoyos Iruarrizaga y Saiz Santos 2014).

"Ángel latente (ES y AM): inversor que no está en activo, ya que no ha invertido en los últimos tres años en ninguna start-up, aunque sí lo hizo con anterioridad (LACES Interreg España-Portugal).

» Business angel tecnológico (ES)/ángel tecnológico (ES): inversor privado que invierte en proyectos de contenido altamente tecnológico (Colomer i Espinet et al. 2009).

"Business angel empresarial (ES y AM): directivo o ejecutivo de empresa en activo, prejubilado o jubilado que se implica mucho en la actividad y la gestión de la empresa en la que ha invertido, oscilando su nivel de inversión entre los 50.000 y los 150.000 euros (Colomer i Espinet et al. 2009).

»Business angel trabajador (ES y AM): directivo o ejecutivo de empresa que ha querido dar un giro a su actividad profesional o que ha pasado por un proceso de prejubilación y todavía desea trabajar y aportar un valor añadido constante a la empresa donde ha realizado la inversión, situándose su nivel de inversión entre los 50.000 y 90.000 euros (Colomer i Espinet et al. 2009).

"Business angel consultor (ES y AM) / business angel asesor (ES): Directivo, ejecutivo o profesional que, a pesar de continuar con su actividad empresarial o profesional, quiere transmitir sus conocimientos a los emprendedores que se encuentran al inicio de su proyecto empresarial, generalmente sin aportar capital, sino experiencia y una red de contactos (Colomer i Espinet et al. 2009).

» Business angel financiero (ES y AM): empresario que, aunque aporta valor a la empresa, no se implica demasiado en su gestión, ya que básicamente su objetivo es obtener una futura rentabilidad sobre el capital aportado, situándose su nivel de inversión entre los 150.000 y 300.000 euros (Colomer i Espinet et al. 2009).

" Business devil: inversor privado con una participación superior al 50\% del capital social de la iniciativa de negocio (Hoyos Iruarrizaga y Saiz Santos 2014). Inversor privado que se aprovecha negativamente de la inexperiencia del emprendedor (Schramm 2010).

Además de la oposición maniquea entre "ángeles" y "demonios", algunos autores explotan al máximo las metáforas religiosas. Si Hindle y Wenban distinguían ya entre "serafines" y "querubines" $(1999,16)$, y de Torres Carbonell $(2012,54)$ establece un parangón entre el papel que desempeñan los miembros de una red de business angels y las jerarquías bíblicas: 
Profeta: Es el que más conocimientos tiene como inversor y generalmente es el que más invierte. Sirve como mentor de los emprendedores jóvenes.

Querubines: Son inversores jóvenes que juegan un rol clave. Aportan riesgo y adrenalina.

Discípulos: Siempre existe un grupo de ángeles con poca experiencia técnica pero que son curiosos y quieren invertir en sectores que no conocen. Se benefician de los inversores con más experiencia, pero también aportan perspectivas frescas.

Mortales: Van a las reuniones no para invertir sino para prestar sus servicios, generar networking y apoyar a emprendedores.

Llama la atención que precisamente estas unidades monoléxicas sean las que menos testimonios presentan en los corpora (solo un par de ocurrencias), frente al predominio de las unidades sintagmáticas. Una nota al pie de Hindle y Wenban $(1999,8, n .4)$, en la que los autores confiesan que fueron "incapaces de resistirse" a recurrir a estas categorías descriptivas, da cuenta de las dosis de creatividad que a veces rezuman los textos especializados $^{6}$.

En consecuencia, por lo que respecta a los hipónimos de business angel, de los cuales hemos recogido las categorías más frecuentes en los textos, resulta difícil prever cuándo se estabilizará la creación neológica, dado que, al tratarse de un campo en expansión, pueden surgir nuevas necesidades denominativas. Así, en el marco de las redes o sindicatos de business angels - de ellos hablaremos en el siguiente apartado-destaca la figura del responsable, denominado respectivamente lead angel, "ángel líder", y gatekeeper, "guardián" o "portero", aunque los textos no suelen ofrecer todavía equivalencias de uso reales, sino simplemente explicaciones sobre la terminología anglosajona (por ejemplo, Vinyes i Vila 2013, 81). Para el lego, algunos de estos distingos pueden resultar exagerados e incluso superfluos ("neologismos de lujo" o "expresivos"). No obstante, como señala Sablayrolles (2016, 45 y ss.) al refutar algunas creencias generalizadas sobre la neología, si un neologismo nos parece innecesario, probablemente será porque no pertenezcamos al círculo donde se utiliza: "nada ocurre sin una razón y los hablantes que se molestan en crear nuevas lexías o nuevos usos deben de tener una motivación para hacerlo". Resulta prudente, pues, dejar transcurrir un período de tiempo para estudiar la implantación de los términos y comprobar cuáles se han consolidado y cuáles, por el contrario, no han pasado de infructuosas propuestas neológicas.

6 Esta actitud lúdica no se limita a la creación de neónimos, sino que se extiende también a los titulares y al cuerpo de los textos, con ejemplos como estos: “Un país sin ángeles” (Suárez Sánchez-Ocaña, 2013); “Los business angels sí tienen sexo" (El Mundo, 31/03/2017); "Los ángeles inversores vuelan en grupo para atenuar riesgos [...] Apple, Amazon, Starbucks, Facebook y otras muchas empresas nacieron bajo las alas de inversores ángeles" (Scarpinelli 2014); "Relación poco angelical” (Bedoya Madrid 2016); "Ángeles que pueden convertirse en 'diablos”" (Ayala Pintado y González Alvarado 2010, 25); “No hay que esperar ningún milagro: los ángeles no bajarán del cielo” (Asheesh Advani, citado en Sánchez Torres 2012, 85). 


\section{Términos relacionados}

Finalmente, presentamos los resultados de los corpora para los términos pertenecientes a la familia léxica del business angel, así como los que se refieren a sus grupos o redes:

\begin{tabular}{|c|c|c|}
\hline Término & Frecuencia & Tipo de unidad \\
\hline inversión ángel & 102 & Sintagma $(N+N)$ \\
\hline mercado ángel & 42 & Sintagma $(N+N)$ \\
\hline capital ángel & 8 & Sintagma $(N+N)$ \\
\hline financiación ángel & 7 & Sintagma $(N+N)$ \\
\hline población ángel & 7 & Sintagma $(N+N)$ \\
\hline inversión de business angels & 7 & Sintagma (N + S. Prep) \\
\hline red de business angels & 364 & Sintagma (N + S. Prep) \\
\hline BAN & 153 & Sigla de business angels network \\
\hline business angels network & 116 & Extranjerismo crudo (Sintagma $[\mathrm{N}+\mathrm{N}+\mathrm{N}])$ \\
\hline RAI & 65 & Sigla de red de ángeles inversores \\
\hline red de ángeles inversores & 47 & Sintagma $(N+$ S. Prep $)$ \\
\hline RBA & 24 & Sigla de red de business angels \\
\hline red de $B A$ & 22 & $\begin{array}{l}\text { Sintagma ( } \mathrm{N}+\mathrm{S} \text {. Prep [sigla de business } \\
\text { angels] })\end{array}$ \\
\hline red business angel & 12 & Sintagma $(N+N+N)$ \\
\hline grupo de business angels & 8 & Sintagma $(N+$ S. Prep) \\
\hline sindicato de ángeles & 4 & Sintagma $(N+S$. Prep $)$ \\
\hline red de inversores ángel & 2 & Sintagma (N + S. Prep) \\
\hline alianza de ángeles & 1 & Sintagma (N + S. Prep) \\
\hline alianza de $B A$ & 1 & $\begin{array}{c}\text { Sintagma }(\mathrm{N}+\mathrm{S} \text {. Prep [sigla de business } \\
\text { angels] })\end{array}$ \\
\hline alianza de business angels & 1 & Sintagma $(N+$ S. Prep $)$ \\
\hline business angels club & 1 & Extranjerismo crudo (Sintagma $[\mathrm{N}+\mathrm{N}+\mathrm{N}])$ \\
\hline
\end{tabular}

Tabla 3. Términos relacionados con business angel en el corpus de España. 


\begin{tabular}{|c|c|c|}
\hline Término & Frecuencia & Tipo de unidad \\
\hline inversión ángel & 119 & Sintagma $(N+N)$ \\
\hline capital ángel & 15 & Sintagma $(N+N)$ \\
\hline mercado ángel & 2 & Sintagma $(N+N)$ \\
\hline financiamiento ángel & 1 & Sintagma $(N+N)$ \\
\hline red de ángeles inversionistas & 64 & Sintagma (N + S. Prep) \\
\hline red de Al & 52 & $\begin{array}{c}\text { Sintagma ( } \mathrm{N}+\mathrm{S} \text {. Prep [sigla de ángeles } \\
\text { inversionistas]) }\end{array}$ \\
\hline red de business angels & 27 & Sintagma (N + S. Prep) \\
\hline$B A C$ & 22 & Sigla de business angels club \\
\hline red de inversionistas ángeles & 19 & Sintagma (N + S. Prep) \\
\hline business angels club & 16 & Extranjerismo crudo (Sintagma $[N+N+N]$ ) \\
\hline red de inversores ángeles & 12 & Sintagma (N + S. Prep) \\
\hline business angels network & 6 & Extranjerismo crudo (Sintagma $[N+N+N]$ ) \\
\hline BAN & 6 & Sigla de business angels network \\
\hline club de inversores ángeles & 4 & Sintagma (N + S. Prep) \\
\hline club de ángeles inversionistas & 2 & Sintagma (N + S. Prep) \\
\hline grupo de inversionistas ángeles & 2 & Sintagma (N + S. Prep) \\
\hline red de ángeles inversores & 2 & Sintagma $(N+S$. Prep $)$ \\
\hline club de ángeles de negocios & 1 & Sintagma (N + S. Prep) \\
\hline club de inversionistas ángeles & 1 & Sintagma (N + S. Prep) \\
\hline grupo de ángeles inversionistas & 1 & Sintagma (N + S. Prep) \\
\hline grupo de inversores ángeles & 1 & Sintagma (N + S. Prep) \\
\hline red de ángeles aportadores & 1 & Sintagma (N + S. Prep) \\
\hline
\end{tabular}

Tabla 4. Términos relacionados con business angel en el corpus de América.

Las construcciones del primer grupo son análogas al sintagma "inversor ángel". En particular "inversión ángel" registra una alta frecuencia en ambos corpora y se puede considerar implantada en las dos orillas. En cuanto a las asociaciones que actúan como nexo entre los inversores potenciales y los emprendedores que necesitan fondos para sus proyectos, se crean nuevos sintagmas con las bases "red", "sindicato", "grupo", "club", "alianza", y las que eran las unidades más frecuentes en las tablas 1 y 2 (las distintas combinaciones dan lugar a una alta variación denominativa). Además, se utilizan los extranjerismos crudos business angels network y business angels club, así como las siglas correspondientes BAN y BAC. En España encontramos asimismo RAI, a partir de red de ángeles inversores, y la sigla híbrida $R B A$, red de business angels. Para una delimitación conceptual precisa de estas unidades, puede consultarse Vinyes i Vila 2013, 80-81. Mientras que las redes se limitarían básicamente a presentar al emprendedor y al inversor, los sindicatos facilitan a sus miembros todo el proceso posterior gracias a la presencia del mencionado gatekeeper. Por su parte, los clubes suelen tener menos de diez miembros y proporcionan algún 
tipo de formación a sus miembros, mientras que las alianzas se podrían considerar "redes de redes" o grupos regionales de ángeles que realizan inversiones sindicadas.

\section{A modo de conclusión}

A lo largo de este artículo hemos analizado un proceso neológico específico que se encuentra en estado de evolución. Resulta arriesgado realizar una hipótesis sobre cómo progresará el campo. Casi la única certeza es que, como demuestran los resultados, el experto o intermediario introducirá en algún momento business angel entre sus palabras clave, si desea, por ejemplo, que su publicación sea identificada rápidamente por los buscadores y llegue al mayor número de personas. Los argumentos lingüísticos de formación de palabras, que nos llevarían a aconsejar "inversor ángel", válido en los dos continentes y análogo a "inversión ángel", no siempre tienen prioridad (recuérdese la batalla que, no hace mucho, perdió "mundialización" contra "globalización").

No queremos terminar sin mencionar el género femenino. Según concluye el informe de la Asociación Española de Business Angels para 2017 (Roure y de San José 2017, 5), los ángeles en España son, en un 91\%, de sexo masculino. ¿Y cómo se denomina al 9\% restante? La Fundéu (2013) recomienda usar "madrina inversora", que no presenta ninguna ocurrencia en nuestro corpus, salvo esta. Por el contrario, "mujer ángel" (es más frecuente el plural "mujeres ángeles" que "mujeres ángel") registra 54 ocurrencias. También aparece "ángel mujer" (2), "mujer business angel" (3) y "red de mujeres business angels" (2). Quizás un sintagma como "inversora ángel" sería más adecuado, ya que proporciona una indicación del género sin utilizar un núcleo que ponga el foco más en el sexo que en las habilidades profesionales. En el corpus de América no encontramos signos lingüísticos de esta distinción, si bien algunos medios sostienen que ya hace algunos años el 11\% de los business angels del continente eran mujeres (La Razón, Montevideo, 24/05/2015). En cualquier caso, la implantación de alguno de estos últimos sintagmas que hemos mencionado dependerá de cómo evolucionen los neologismos para el business angel en general. 


\section{Q Bibliografía}

》 Ayala Pintado, Dolores B. y Mayra Y. González Alvarado. 2010. Ángeles inversores, una nueva modalidad de financiamiento para los emprendimientos en Latinoamérica. Cuenca: Universidad de Cuenca (Ecuador).

" Bancat.com. 2017. "El 79\% de las operaciones de 'ángeles inversores' son locales". Fecha de consulta, 27 de abril de 2021. http://www.bancat.com/es/2017/10/26/noticianaco/

» Bedoya Madrid, Claudia. 2016. “'Ángeles inversionistas’, alternativa de financiación”. Revista Universidad EAFIT vol 1, ํㅜ 167: 64-67.

" Cabré Castellví, M. Teresa. 2005. La terminología: representación y comunicación. Elementos para una teoría de base comunicativa y otros artículos. Barcelona: IULA, Universitat Pompeu Fabra.

" Cabré Castellví, M. Teresa. y Rosa Estopà Bagot. 2005. “Unidades de conocimiento especializado: caracterización y tipología". En Coneixement, llenguatge i discurs especializat, editado por M. T. Cabré Castellví y C. Bach Martorell, 69-93. Barcelona: IULA, Universitat Pompeu Fabra.

》 Cartagena, Nelson. 2009. La contribución de España a la teoría de la traducción. Introducción al estudio y antología de textos de los siglos XIV y XV. Madrid: Iberoamericana; Frankfurt am Main: Vervuert.

»Colomer i Espinet, Albert, Guillem Arís, Jordi Clos, Àlex d'Espona y Melanie Queralt. 2009. Los Business Angels, innovando en la cultura de financiación de las empresas. Madrid: División de Información, Documentación y Publicaciones del Ministerio de Industria, Comercio y Turismo, Gobierno de España.

"Coveney, Patrick y Karl Moore. 1988. Business Angels. Securing start up finance. Chichester, New York: Wiley.

》 de Torres Carbonell, Silvia. 2012. "Fuentes de financiamiento para innovadores en Argentina: venture capital, inversores ángeles, inversores institucionales". Revista de la Bolsa de Comercio de Rosario no 1517: 50-57.

»Diario Financiero. 2018. “La inversión ángel todavía no despega en Chile”, 28/05/2018. Santiago: Grupo DF, Capital ED.

"Díaz-Granados Guida, S., C. A. de Hart Pinto y J. Domínguez Rivera. 2011. Manual para la creación y operación de redes de ángeles inversionistas. Ministerio de Comercio, Industria y Turismo, República de Colombia. Medellín: CREAME.

"El Mundo. 2017. “Los business angels sí tienen sexo", 31/03/2017. Fecha de consulta, 27 de abril de 2021. http://www.elmundo.es/economia/2017/03/27/58d92bf2e2704e173d8b 467d.html

" Freixa, Judit. 2005. "La variació denominativa a través de la variació vertical". En Coneixement, llenguatge i discurs especializat, editado por M. T. Cabré Castellví y C. Bach Martorell,113-131. Barcelona: IULA, Universitat Pompeu Fabra.

» Fundéu BBVA. Buscador urgente de dudas. 2013. "Padrino inversor o padrino empresarial mejor que business angel". Fecha de consulta, 27 de abril de 2021. https://www.fundeu. es/recomendacion/padrino-inversor-padrino-empresarial-mejor-que-business-angel/

" García Martínez, Alberto. 2014. Capital riesgo y business angels como alternativas de fi- 
nanciación para las pequeñas y medianas empresas en España. Valladolid: Universidad de Valladolid.

» Hindle, Kevin y Robert Wenban. 1999. “Australia’s Informal Venture Capitalists: An Exploratory Profile". Venture Capital 1, ํㅡ 2: 169-186.

"Hoffmann, Lothar. 1985. Kommunikationsmittel Fachsprache. Eine Einführung. Tübingen: Günter Narr.

» Hoyos Iruarrizaga, Jon y Ana Blanco Mendialdua. 2014. Financiación del proceso emprendedor. Madrid: Pirámide.

》 Hoyos Iruarrizaga, Jon y María Saiz Santos. 2014. Business angels. Los mecenas del ecosistema emprendedor. Madrid: ESIC.

" Jakobson, Roman. 1959. "On linguistic aspects of translation". En On Translation, editado por A. Brower Reuben,232-239. Cambridge, Mass.: Harvard University Press.

"La Razón. 2015. “Crecen 'inversiones ángel’ en América Latina”, 24/05/2015. Montevideo: EFE. Fecha de consulta, 27 de abril de 2021. https://www.la-razon.com/financiero/2015/05/24/crecen-inversiones-angel-en-america-latina-4/

» LACES - Interreg España-Portugal. (s.a.). Los business angels como fuente de financiación para las entidades de economía. Financiando la economía social, Universidad de Santiago de Compostela, Xunta de Galicia et al.

» Montero Simó, M. 2013. “Incentivos fiscales para los business angels en España”. Revesco: Revista de estudios cooperativos 112: 213-239.

» Morales, Carlos. 2015. “¿Cómo es un inversionista ángel en 2015?”. Forbes México. Fecha de consulta, 27 de abril de 2021. https://www.forbes.com.mx/como-es-un-inversionistaangel-en-2015/

" Olmos García, Mónica. 2014. Startups: vías de financiación alternativa. Madrid: Universidad Pontificia de Comillas, ICADE.

» Otero Barros, Carlos. 2015. "¿Cuánta TIR tienes que ofrecer a tu business angel? Descubre por qué Sillicon Valley sólo invierte en empresas fuertemente escalables". Odisea Digital: El blog de Carlos Otero. Fecha de consulta, 27 de abril de 2021. https:// medium.com/@coterobarros/cu\%C3\%A1nta-tir-tienes-que-ofrecer-a-tu-business-angel-632ed1aoe6b8

"Parc Científic Universitat de València. 2017. "Qué es y cómo trabaja un business angel". Fecha de consulta, 27 de abril de 2021. https://news.pcuv.es/qu\%C3\%A9-es-yc\% $3 \%$ B3mo-trabaja-un-business-angel

»Pruvost, Jean y Jean-François Sablayrolles. 2003. Les néologismes. Paris: Presses Universitaires de France.

》Real Academia Española y Asociación de Academias de la Lengua Española. 2005. Diccionario panhispánico de dudas. Madrid: Santillana Ediciones Generales.

》 Romaní, Gianni y Miguel Atienza. 2017. Inversión ángel en Chile. Informe nacional 2016. Santiago: Universidad Católica del Norte.

» Roure Juan y Amparo de San José. 2017. Informe Business Angels Aeban 2017. La inversión ángel en España: Cómo se inician los inversores, dónde se encuentran las oportunidades y qué les haría invertir más. Asociación Española Business Angels (AEBAN).

"Roure Juan, Amparo de San José y Juan Luis Segurado. 2013. Las redes de inversionistas ángeles en América Latina y el Caribe. Fondo Multilateral de Inversiones, Grupo Banco Interamericano de Desarrollo. 
"Rufino Bengoechea, Eneko. 2011. "La realidad de los business angels y la necesidad de marco fiscal: propuesta de lege ferenda". Blog de CIALT, Asesores Legales y Tributarios. Fecha de consulta, 27 de abril de 2021. http://www.cialt.com/la-realidad-de-losbusiness-angels-y-la-necesidad-de-marco-fiscal-propuesta-de-lege-ferenda/

"Ruiz Igoa, Matías A. 2016. Ángeles inversores. Alternativa financiera para emprendimientos. Córdoba (Argentina): Universidad Siglo 21.

»Sablayrolles, Jean-François. 2016. “Néologismes et idées reçues”. En La neología en las lenguas románicas: recursos, estrategias y nuevas orientaciones, editado por J. García Palacios, G. de Sterck, D. Linder, N. Maroto, M.

» Sánchez Torres, Denisse E. 2012. Análisis del emprendedor y del emprendimiento de éxito en el Ecuador para incentivar la creación de una red de inversionistas ángeles en Quito. Quito: Pontificia Universidad Católica del Ecuador.

"Scarpinelli, Luján. 2014. "Los ángeles inversores vuelan en grupo para atenuar riesgos", 16/11/2014. La Nación (Argentina).

"Schramm, Martin. 2010. Business Angels and Business Angels Networks: Benchmarking South Tyrol in an international context. Bozen: Free University of Bozen-Bolzano.

"Suárez Sánchez-Ocaña, Alejandro. 2013. "Un país sin ángeles (inversores)", 31/01/2013. El Mundo. Fecha de consulta, 27 de abril de 2021. http://www.elmundo.es/blogs/elmundo/hay-un-guru-en-mi-sopa/2013/01/31/un-pais-sin-angeles-inversores.html

»Viel, Matías. 2014. Inversores ángeles en Argentina. Criterios de selección de inversiones. Buenos Aires: Universidad de San Andrés.

»Vinyes i Vila, Jesús. 2013. Factores condicionantes de la aparición y desarrollo de los ángeles inversores: el caso de Cataluña. Vic: Universitat de Vic. 